\title{
Childhood lead poisoning: an overview
}

\author{
KL Hon *, CK Fung, Alexander KC Leung
}

\section{A B S T R A C T}

Childhood lead poisoning is a major public health concern in many countries. In 2015, the Hong Kong SAR Government and its citizens faced a major public health crisis due to the presence of lead in the drinking water of a number of public housing estates. Fortunately, no child was diagnosed with lead poisoning that required treatment with chelation. Lead is a ubiquitous, naturally occurring material that exists in air, dust, soil, and water. It is also widely present in industrial products including petrol, paints, ceramics, food cans, candies, cosmetics, traditional remedies, batteries, solder, stained glass, crystal vessels, ammunition, ceramic glazes, jewellry, and toys. It can also be found in human milk. There is no safe blood lead level and it may be impossible to completely eliminate lead from any city. Hence routine measurement of blood lead levels is not considered useful. Acute poisoning, especially with encephalopathy, deserves immediate medical treatment in hospital. Chelation therapy is recommended if blood lead level is $45 \mu \mathrm{g} / \mathrm{dL}$ or higher. For blood levels between 20 and $45 \mu \mathrm{g} / \mathrm{dL}$, treatment is indicated if the child is symptomatic. For blood levels below $20 \mu \mathrm{g} / \mathrm{dL}$ in otherwise asymptomatic children, the principle of treatment is to provide long-term neurodevelopmental follow-up and counselling. In all cases, immediate removal of the source of lead exposure is vital. Even low levels of lead exposure can significantly impair learning, educational attainment, and neurodevelopment.

\section{Hong Kong Med J 2017;23:616-21}

DOI: $10.12809 / \mathrm{hkmj} 176214$

${ }^{1} \mathrm{KL} \mathrm{Hon}$ *, MD, FAAP

${ }^{2}$ CK Fung, $M B, C h B$

${ }^{3}$ AKC Leung, FRCP(UK), FRCPCH

${ }^{1}$ Department of Paediatrics, Prince of Wales Hospital, The Chinese University of Hong Kong, Shatin, Hong Kong

2 Department of Anatomical and Cellular Pathology, United Christian Hospital, Kwun Tong, Hong Kong

Department of Pediatrics, Alberta Children's Hospital, University of Calgary, Calgary, Alberta, Canada

* Corresponding author: ehon@cuhk.edu.hk

\section{Introduction}

Childhood lead poisoning is a major public health concern in many countries as it may result in serious health consequences. In general, children absorb a greater percentage of lead from the gastrointestinal tract than adults. ${ }^{1,2}$ Fasting, iron deficiency, and calcium deficiency may further increase gastrointestinal absorption of lead., ${ }^{1,2}$ In Hong Kong, food safety has become a major public concern in recent years. In 2015, the Hong Kong SAR Government and its citizens faced a major public health crisis due to the presence of lead in the drinking water of a number of public housing estates. Fortunately, no child was diagnosed with lead poisoning and hence did not require chelation therapy.

This review discusses the possible sources of lead exposure and poisoning in children, public health implications, medical management, and neurodevelopmental outcomes with a focus on the situation in Hong Kong. References were searched in January 2017 using keywords: (("toxicity") OR ("poisoning") AND "lead") AND (("lead toxicity") OR ("lead poisoning") AND "Hong Kong") in PubMed, limited to 'human', with no filters for article type or date of publication. Discussion is based on, but not limited to, the search results.

\section{Possible sources of lead exposure and poisoning in children}

According to the World Health Organization, lead is a ubiquitous, naturally occurring material that exists in air, dust, soil, and water. It is also widely present in industrial products including petrol, paints, ceramics, food cans, candies, cosmetics, traditional remedies, batteries, solder, stained glass, crystal vessels, ammunition, ceramic glazes, jewellry, and toys. ${ }^{3-7}$ It is also found in human breast milk. ${ }^{8}$ In the US, leadcontaining paint in old houses is one of the main sources of lead exposure or poisoning in children. In many industrialising countries including China, smelters, refineries, mines, soil contamination, and use of lead gasoline are important sources of lead exposure.

Water supply can be contaminated with lead. ${ }^{9-12}$ A recent example is the drinking water crisis that occurred in the post-industrial city of Flint in Michigan, US. ${ }^{11}$ In this situation, lead in drinking water is absorbed to a greater extent than lead in food and may account for more than $50 \%$ of the lead ingested by children. ${ }^{13}$ The US Environmental Protection Agency recommended taking actions when lead in drinking water exceeds 15 parts per billion, including taking further steps to optimise their corrosion-control treatment (for water 
systems serving 50000 people who have not fully optimised their corrosion control), educating the public about lead in drinking water and actions consumers can take to reduce their exposure to lead, replacing the portions of lead service lines (lines that connect distribution mains to customers) under the water system's control. ${ }^{14}$ Most incidents of lead contamination of household water were caused by copper plumbing with lead solder. Occasionally, lead pipes may also be responsible although they are now rarely used.

No review article about lead toxicity in Hong Kong was found on MEDLINE/PubMed at the time of writing. Nevertheless discrete reports from different institutes about local lead toxicity are available, with the earliest report dated 1969, when 121 Gurkha soldiers investigated for 'epidemic myalgia' were found to have lead poisoning due to curry powder contaminated with lead chromate. ${ }^{5}$ Later in 1977, a 4-month-old girl presented with a grand mal seizure after ingestion of Chinese herbal medicines containing lead. ${ }^{3}$ In 1991, a case of acute lead poisoning with cerebral oedema and death was reported in a 2-month-old girl. ${ }^{15}$ Two other case reports described a total of four adult patients who had lead poisoning following ingestion of two different Chinese herbal pills. They had variable clinical presentations ranging from relatively asymptomatic to end-organ complications. ${ }^{16,17}$ In 2014, a middle-aged woman who presented with motor neuron disease was found to have a raised blood lead level after consumption of ashes from burnt Chinese talismans (Dao religious handwriting believed to have the power to expel evil) ${ }^{18}$ Hong Kong is a commercialised city with very few industries and factories. The main sources of lead are contaminated food, toys, adulterated medicines, traditional remedies, and batteries. A study of children with eczema revealed that disease severity and quality of life correlated with blood lead level, and patients who had used traditional herbal remedies generally had a higher blood lead level. ${ }^{19}$ Contaminated water in public housing estates was first described in 2015 in Hong Kong. ${ }^{20}$

\section{Potential public health implications}

There is no screening programme for lead or other heavy metals in Hong Kong. Guidelines about lead screening, however, are available worldwide. In 2013, nearly 30 questionnaires were available, designed as a preliminary screening tool for paediatric lead poisoning. They showed variable sensitivity and specificity based on systematic reviews. ${ }^{21,22}$ According to the latest guideline in 2012 from the Centers for Disease Control and Prevention (CDC)'s Advisory Committee on Childhood Lead Poisoning Prevention (ACCLPP), clinicians should perform

\section{兒童鉛中毒的概述 \\ 韓錦倫、馮靖淇、梁國柱}

兒童鉛中毒是許多國家的主要公共衛生問題。2015年香港部分公共屋 邨發現飲用水含鉛，令特區政府及市民面臨重大的公共衛生危機。可 幸的是沒有兒童被診斷患有鉛中毒而需接受螯合治療。鉛是一種天然 物質, 存在於周圍環境中, 如空氣、灰塵、土壤和水。鉛亦廣泛使用 於工業用品中, 例如汽油、油漆、陶瓷、食品罐頭、糖果、化妝品、 傳統療法、電池、焊錫、彩色玻璃、水晶容器、彈藥、陶瓷婇、珠寶 和玩具等。母乳中也可以找到鉛。沒有所謂安全的血鉛濃度水平, 也 沒有可能在任何一個城市徹底消除鉛這種物質。因此, 恆常測量血鉛 水平被認為沒有作用。急性鉛中毒尤其是涉及腦部的情況時必須立刻 入院接受治療。如果血鉛水平達至 $45 \mu \mathrm{g} / \mathrm{dL}$ 或以上, 建議使用螯合療 法。血鉛水平處於 20 至 $45 \mu \mathrm{g} / \mathrm{dL}$ 之間而受影響兒童出現症狀時, 便需 要接受治療。對於血鉛水平低於 $20 \mu \mathrm{g} / \mathrm{dL}$ 而無出現症狀的兒童, 治療 原則是長期跟進其神經發育過程和提供輔導。在任何情況下立即離開 鉛暴露的源頭至為重要。即使低水平的鉛暴露也會嚴重影響兒童的學 習、教育程度和神經發育

an environmental assessment before screening children for lead poisoning. ${ }^{13,23}$ This changed the practice of universal screening of all children for elevated blood lead levels ${ }^{2,23,24}$ to targeted screening after mathematical simulations suggested that such screening among 1-year-old children may not be cost-effective, especially in communities with a lower prevalence of lead poisoning. ${ }^{25}$ At the same time, with reference to the level of 'lead toxicity' in children, ACCLPP eliminated the term 'level of concern' for blood lead level (previously defined as $10 \mu \mathrm{g} / \mathrm{dL}$ ) and replaced it with a reference level of $5 \mu \mathrm{g} / \mathrm{dL}$, based on the 97.5th percentile of the population blood lead level in children aged between 1 and 5 years. ${ }^{2,13,24}$ This was supported by the American Academy of Pediatrics who acknowledged that even the lowest degree of lead exposure might harm children, ${ }^{13,23,26}$ and echoed the European Food Safety Authority who concluded that there is no known safe exposure to lead as evidenced by international studies in Europe. ${ }^{27-29}$ In other words, there is no safe or 'non-toxic' blood lead level.

A systematic review of the effectiveness of interventions to reduce lead exposure from consumer products and drinking water in Germany concluded that the limited quantity and quality of the evidence derived from measuring blood lead level and associated health outcomes suggested an urgent need for more robust research into the effectiveness of interventions to reduce lead exposure from consumer products and drinking water, especially for regulatory interventions. ${ }^{6}$ The dilemma is that there is no safe lead level, and it is 
impossible to completely eliminate lead from any city. Hence routine measurement of blood lead level is not considered useful for management.

\section{Clinical manifestations/ complications of lead poisoning}

Lead is a potent neurotoxin. Neurotoxicity is more prominent in children and infants in-utero than in adults because of the incomplete blood-brain barrier. ${ }^{8,30,31}$ Despite this, the majority of children with lead poisoning is asymptomatic. Neurological manifestations/complications of lead poisoning include acute encephalopathy, peripheral neuropathy, hearing loss, and neurobehavioural deficits such as hyperactivity, withdrawal, developmental delay, lower intelligence quotient, higher academic failure, and lower overall life achievements. ${ }^{32-34}$ Metaanalysis of 19 studies with a total of 8561 children suggested that lead exposure is positively related to conduct problems. ${ }^{35}$ The causal effect of lead exposure on these behavioural problems, however, cannot be proven as poor housing, poverty, and other stressors are significant confounding factors. ${ }^{36}$ According to the American Academy of Neurology, the clinical correlation of mildly elevated but nontoxic levels of blood lead with developmental status remains controversial.

Lead lines at the junction of the gums and teeth, if present, suggest severe and prolonged lead exposure. Other clinical manifestations/ complications include colicky abdominal pain, constipation, growth retardation, vitamin D deficiency, anaemia, and nephropathy. ${ }^{1,224}$ Rarely, lead poisoning may also lead to hypertension, immunodeficiency, osteoporosis, changes in serum level of sex hormones and thyroid hormones, premature delivery, pre-eclampsia, infertility, and malignancy. ${ }^{30,37,38}$

\section{Exposure versus poisoning}

Despite the potential harmful effects of lead on humans, lead exposure is not synonymous with lead toxicity. According to the Agency for Toxic Substances and Disease Registry, exposure is defined as contact with a substance by swallowing, breathing, or touching the skin or eyes. Exposure may be shortterm (acute exposure), of intermediate duration, or long-term (chronic exposure). A toxic agent is a chemical or physical (eg radiation, heat, cold, microwaves) agent that, under certain circumstances of exposure, can cause harmful effects to living organisms (https://www.atsdr.cdc.gov/glossary.html). In other words, it is the lead toxicity per se not lead exposure that necessitates treatment. Although there is no definitive toxic level for blood lead, the affected child should be continuously monitored to ensure medical intervention if necessary.

\section{Screening of children for lead poisoning}

The American Academy of Neurology suggests screening of children with developmental delay for lead toxicity. This should target those with known identifiable risk factors for excessive lead exposure, including children aged 1 to 2 years living in housing built before 1950, exposure to lead-containing folk remedies, child immigrants from countries where lead poisoning is prevalent, children with iron deficiency, children with developmental delay with pica disorder, victims of neglect, and children of low-income families. ${ }^{39}$

The CDC's ACCLPP has updated its guidelines for blood lead screening among children eligible for Medicaid by providing recommendations to improve screening and information for health care providers, state officials, and others interested in lead-related services for Medicaid-eligible children. ${ }^{40}$ Because state and local officials are more familiar than federal agencies with local risks for elevated blood lead levels, the $\mathrm{CDC}$ recommends that state and local officials have the flexibility to develop blood lead screening strategies that reflect local risk. Rather than provision of universal screening to all Medicaid children, which was previously recommended, state and local officials should target screening towards specific groups of children in their area at higher risk. The updated CDC recommendations provide strategies to (1) improve screening rates of children at risk of an elevated blood lead level, (2) develop surveillance policies that are not solely dependent on blood lead level testing, and (3) assist states with evaluation of screening plans.

Neurocognitive impairment in children is a grave concern as it may be irreversible. The current policy in Hong Kong is to perform lead exposure risk assessment in citizens with a borderline raised blood lead level, and carry out developmental assessment in affected children under the age of 12 years, while continuously monitoring all citizens with raised blood lead levels. The threshold for further management for children under 18 years, pregnant women, and lactating mothers is lower than that for the general adult population. This strategy correlates with the targeted screening promoted by the ACCLPP.

\section{Medical management protocol for childhood lead poisoning}

The protocol of management according to blood lead level, adopted from 'Care plan for residents of public estates with elevated lead level in drinking water', was last updated on 28 August 2015 by the Centre for Health Protection, Hong Kong SAR. ${ }^{41}$

Management of patients with lead exposure involves not only the pharmacological management 
of toxicity, but also strategies for intervention and prevention of further exposure. Once an elevated lead level is found, the local health department should be notified and a home risk assessment performed to determine the need for abatement strategies. With the gradual lowering of the 'blood lead level of concern' by the CDC, the threshold for action has also decreased. The Pediatric Environmental Health Specialty Units have made recommendations for further evaluation and/or intervention based on the blood lead level. ${ }^{42}$

In all cases, identification and immediate removal of the source of lead exposure from the child's environment is crucial to the successful management of the patient. Medical treatment of lead poisoning is relatively straightforward. . $^{40,43}$ There is no benefit in prescribing activated charcoal for lead ingestion since it binds lead poorly. Gastric lavage may be performed although the American Academy of Clinical Toxicology stated that there is no evidence to show that its use improves clinical outcome. Whole bowel irrigation has a theoretical benefit for decontamination of heavy metal ingestion but there are insufficient data at present to support or exclude its use.

For blood lead level between 20 and $45 \mu \mathrm{g} / \mathrm{dL}$, the minimum medical management for children is to decrease their exposure to all sources of lead, to correct any iron deficiency and maintain an adequate calcium intake, and to test frequently to ensure that the child's blood lead levels are decreasing. Although not approved by the CDC, some clinicians prescribe D-penicillamine for children within this range of blood lead level. Otherwise the patient should have a confirmatory venous blood lead level measured within 1 to 4 weeks as a venous sample is subjected to less contamination than a capillary one. A capillary blood sampling protocol has also been documented by the CDC, and is more practical than venous blood sampling, especially in infants. For blood lead level of $<20 \mu \mathrm{g} / \mathrm{dL}$ in otherwise asymptomatic children, the principle of treatment is to provide long-term neurodevelopmental follow-up and counselling as well as periodic blood sampling to ensure lead level is not increasing and to continue until the level is $<5 \mu \mathrm{g} / \mathrm{dL}$. $^{40,43-46}$ For symptomatic patients with blood lead level of $<20 \mu \mathrm{g} / \mathrm{dL}$, sequential measurements of blood lead level along with review of the child's clinical status should be done at least every 3 months. Iron deficiency should be treated promptly. Children with blood lead levels in this range should be referred for environmental investigation and management. Identifying and eradicating all sources of excessive lead exposure is the most important intervention for decreasing blood lead levels.

Chelation therapy is recommended if the patient has a blood lead level of $\geq 45 \mu \mathrm{g} / \mathrm{dL}$. Before starting therapy, the blood lead measurement must be repeated immediately for confirmation but treatment should not be delayed while awaiting the result if encephalopathy is suspected. Chelation therapy, especially in the setting of encephalopathy, can be complicated. The patient must be admitted to a hospital with at least a physician who has proficiency with chelation therapy and management of childhood lead poisoning. The decision as to which agent should be used depends on the blood lead level, the symptomatology, and the environmental lead burden. Intravenous fluids should be given if necessary to ensure adequate urine output to permit chelation and excretion of lead in the body. ${ }^{2,47}$ Fluid intake and output should be monitored to permit early detection of inappropriate antidiuretic hormone secretion.

Succimer (dimercaptosuccinic acid) is a watersoluble, oral chelating agent that is appropriate for asymptomatic children with a blood lead level of 45 to $69 \mu \mathrm{g} / \mathrm{dL}$. The recommended dose is 10 $\mathrm{mg} / \mathrm{kg}$ or $350 \mathrm{mg} / \mathrm{m}^{2}$ three times per day. ${ }^{47} \mathrm{D}$ penicillamine is a second-line oral chelating agent because of its potential for significant side-effects (thromobocytopenia, leukopaenia, urticaria, angioedema, abnormal liver function, StevensJohnson syndrome, and nephrotic syndrome) ${ }^{47}$

Calcium disodium edetate $\left(\mathrm{CaNa}_{2}\right.$ EDTA) is a chelating agent that is preferably given by continuous intravenous infusion. The recommended dose is 35 to $50 \mathrm{mg} / \mathrm{kg} /$ day or 1000 to $1500 \mathrm{mg} / \mathrm{m}^{2} /$ day. ${ }^{47}$ It should not be used as the sole agent in patients who manifest features of lead encephalopathy, because it does not cross the blood-brain barrier and can potentially lead to exacerbation of lead encephalopathy. Rather, dimercaprol (also referred to as British anti-Lewisite), which does cross the blood-brain barrier, should be used in combination with $\mathrm{CaNa}_{2}$ EDTA. Dimercaprol is a parenteral chelating agent of choice for patients with lead encephalopathy; the recommended dose is 3 to $5 \mathrm{mg}$ every 4 hours given by deep intramuscular injection. Combination therapy with $\mathrm{CaNa}_{2}$ EDTA and dimercaprol or succimer should be instituted in symptomatic children with blood lead level of 45 to $69 \mu \mathrm{g} / \mathrm{dL} .{ }^{2,47}$ Children whose blood lead level is $\geq 70$ $\mu \mathrm{g} / \mathrm{dL}$ should be treated as medical emergencies, preferably with intravenous therapy. A combination of intramuscular dimercaprol and intravenous $\mathrm{CaNa}_{2}$ EDTA should be used for children with blood lead level of 70 to $99 \mu \mathrm{g} / \mathrm{dL}$ if there are features of lead encephalopathy or with a blood lead level of $\geq 100 \mu \mathrm{g} / \mathrm{dL}$ even in the absence of features of lead encephalopathy. Features of lead encephalopathy include persistent lethargy, persistent vomiting, headache, afebrile seizures, or coma.

Chelation therapy has its own limitations. With chronic lead ingestion, lead can be incorporated into the skeletal system and can be an endogenous reservoir of lead exposure that is hard to eliminate..$^{2,47}$ 


\section{Neurodevelopmental outcomes: who and for how long should at-risk children be monitored?}

Lead poisoning in childhood produces long-term problems with learning, intelligence, and earning power. ${ }^{48}$ Asymptomatic lead poisoning has a far better prognosis. Given that there is no safe blood lead level, the CDC stresses the importance of regular follow-up of children with elevated blood lead levels. A monitoring programme should include nutritional support (such as ensuring sufficient intake of calcium, vitamin D, vitamin C) to minimise lead absorption, preventive measures to avoid household lead exposure, and education of caregivers about sources of lead exposure, prevention of exposure, and ways to decrease intestinal absorption. ${ }^{40,44-46}$ Affected children should be followed up continuously at least until environmental sources of lead have been identified and eliminated, and thereafter until blood lead level has declined to $<15 \mu \mathrm{g} / \mathrm{dL}$ for at least 6 months, while other objectives of the management plan are achieved. Long-term neurodevelopmental monitoring is also advised after a case is closed, in view of many of the neurological deficits that manifest late in life. Any surveillance should be continued until a child reaches 6 years of age, an age of critical learning transition points and elevated risk exposure, although the definitive duration of follow-up is unclear. ${ }^{40,43-46}$ Likewise, no end-point of follow-up is recommended by the Centre of Health Protection in Hong Kong.

\section{Conclusions}

It has been established that even low-level lead exposure can significantly impair the learning and educational attainment and neurodevelopment of a child. ${ }^{49-54}$ In-utero exposure to lead can adversely affect the infant's neurodevelopment, independent of postnatal blood lead level. With no safe limit of blood lead level, rigorously reducing the amount of lead in the environment is imperative for young children and unborn babies. ${ }^{13}$

\section{Declaration}

All authors have disclosed no conflicts of interest.

\section{References}

1. Lowry JA. Childhood lead poisoning: clinical manifestations and diagnosis. Available from: https:// www.uptodate.com/contents/childhood-lead-poisoningclinical-manifestations-and-diagnosis. Accessed 2 Jan 2017.

2. Centers for Disease Control (CDC). Preventing lead poisoning in young children-United States. MMWR Morb Mortal Wkly Rep 1985;34:66-8,73.

3. Chan H, Billmeier GJ Jr, Evans WE, Chan H. Lead poisoning from ingestion of Chinese herbal medicine. Clin Toxicol 1977;10:273-81.

4. Chui SH, Wong YH, Chio HI, et al. Study of heavy metal poisoning in frequent users of Chinese medicines in Hong Kong and Macau. Phytother Res 2013;27:859-63.

5. Power JG, Barnes RM, Nash WN, Robinson JD. Lead poisoning in Gurkha soldiers in Hong Kong. Br Med J 1969;3:336-7.

6. Pfadenhauer LM, Burns J, Rohwer A, Rehfuess EA. Effectiveness of interventions to reduce exposure to lead through consumer products and drinking water: a systematic review. Environ Res 2016;147:525-36.

7. Gorospe EC, Gerstenberger SL. Atypical sources of childhood lead poisoning in the United States: a systematic review from 1966-2006. Clin Toxicol (Phila) 2008;46:72837.

8. Koyashiki GA, Paoliello MM, Tchounwou PB. Lead levels in human milk and children's health risk: a systematic review. Rev Environ Health 2010;25:243-53.

9. Falta RW, Bulsara N, Henderson JK, Mayer RA. Leadedgasoline additives still contaminate groundwater. Environ Sci Technol 2005;39:379A-384A.

10. Peplow D, Edmonds R. Health risks associated with contamination of groundwater by abandoned mines near Twisp in Okanogan County, Washington, USA. Environ Geochem Health 2004;26:69-79.

11. Hanna-Attisha M, LaChance J, Sadler RC, Champney Schnepp A. Elevated blood lead levels in children associated with the flint drinking water crisis: a spatial analysis of risk and public health response. Am J Public Health 2016;106:283-90.

12. Brown MJ, Margolis S. Lead in drinking water and human blood lead levels in the United States. MMWR Suppl 2012;61:1-9.

13. Schnur J, John RM. Childhood lead poisoning and the new Centers for Disease Control and Prevention guidelines for lead exposure. J Am Assoc Nurse Pract 2014;26:238-47.

14. Basic information about lead in drinking water. Available from: https://www.epa.gov/ground-water-and-drinkingwater/basic-information-about-lead-drinking-water. Accessed 1 Aug 2017.

15. Wong VC, Ng TH, Yeung CY. Electrophysiologic study in acute lead poisoning. Pediatr Neurol 1991;7:133-6.

16. Auyeung TW, Chang KK, To CH, Mak A, Szeto ML. Three patients with lead poisoning following use of a Chinese herbal pill. Hong Kong Med J 2002;8:60-2.

17. Fung HT, Fung CW, Kam CW. Lead poisoning after ingestion of home-made Chinese medicines. Emerg Med (Fremantle) 2003;15:518-20.

18. Chan CK, Ching CK, Lau FL, Lee HK. Chinese talismans as a source of lead exposure. Hong Kong Med J 2014;20:347-9.

19. Hon KL, Ching GK, Hung EC, Leung TF. Serum lead levels in childhood eczema. Clin Exp Dermatol 2009;34:e508-9.

20. Lee WL, Jia J, Bao Y. Identifying the gaps in practice for combating lead in drinking water in Hong Kong. Int J Environ Res Public Health 2016;13.pii:E970.

21. Ossiander EM. A systematic review of screening questionnaires for childhood lead poisoning. J Public Health Manag Pract 2013;19:E21-9.

22. Burns MS, Shah LH, Marquez ER, et al. Efforts to identify at-risk children for blood lead screening in pediatric clinics-Clark County, Nevada. Clin Pediatr (Phila) 2012;51:1048-55. 
23. Council on Environmental Health. Prevention of childhood lead toxicity. Pediatrics 2016;138.pii:e20161493.

24. Preventing lead poisoning in young children. A statement by the Center for Disease Control. J Pediatr 1978;93:70920.

25. Rolnick SJ, Nordin J, Cherney LM. A comparison of costs of universal versus targeted lead screening for young children. Environ Res 1999;80:84-91.

26. Vorvolakos T, Arseniou S, Samakouri M. There is no safe threshold for lead exposure: a literature review. Psychiatriki 2016;27:204-14.

27. EFSA Panel on Contaminants in the Food Chain (CONTAM). Scientific opinion on lead in food. EFSA J 2010;8:1570

28. Budtz-Jorgensen E, Bellinger D, Lanphear B, Grandjean P; International Pooled Lead Study Investigators. An international pooled analysis for obtaining a benchmark dose for environmental lead exposure in children. Risk Anal 2013;33:450-61.

29. Grandjean P. Even low-dose lead exposure is hazardous. Lancet 2010;376:855-6.

30. Abadin H, Ashizawa A, Stevens YW, et al. Toxicological profile for lead. Atlanta (GA): Agency for Toxic Substances and Disease Registry (US); 2007 Aug.

31. Allen KA. Is prenatal lead exposure a concern in infancy? What is the evidence? Adv Neonatal Care 2015;15:416-20.

32. Evens A, Hryhorczuk D, Lanphear BP, et al. The impact of low-level lead toxicity on school performance among children in the Chicago Public Schools: a population-based retrospective cohort study. Environ Health 2015;14:21.

33. Leung AK, Hon KL. Attention-deficit/hyperactivity disorder. Adv Pediatr 2016;63:255-80.

34. Magzamen S, Imm P, Amato MS, et al. Moderate lead exposure and elementary school end-of-grade examination performance. Ann Epidemiol 2013;23:700-7.

35. Marcus DK, Fulton JJ, Clarke EJ. Lead and conduct problems: a meta-analysis. J Clin Child Adolesc Psychol 2010;39:234-41.

36. Chen A, Cai B, Dietrich KN, Radcliffe J, Rogan WJ. Lead exposure, IQ, and behavior in urban 5- to 7-year-olds: does lead affect behavior only by lowering IQ? Pediatrics 2007;119:e650-8.

37. Mohammed AA, Mohamed FY, El-Okda el-S, Ahmed AB. Blood lead levels and childhood asthma. Indian Pediatr 2015;52:303-6.

38. Kennedy DA, Woodland C, Koren G. Lead exposure, gestational hypertension and pre-eclampsia: a systematic review of cause and effect. J Obstet Gynaecol 2012;32:5127.

39. Shevell M, Ashwal S, Donley D, et al. Practice parameter: evaluation of the child with global developmental delay: report of the Quality Standards Subcommittee of the American Academy of Neurology and The Practice Committee of the Child Neurology Society. Neurology 2003;60:367-80.

40. Wengrovitz AM, Brown MJ; Advisory Committee on Childhood Lead Poisoning, Division of Environmental and Emergency Health Services, National Center for Environmental Health; Centers for Disease Control and Prevention. Recommendations for blood lead screening of Medicaid-eligible children aged 1-5 years: an updated approach to targeting a group at high risk. MMWR Recomm Rep 2009;58(RR-9):1-11.

41. Care plan for residents of public estates with elevated lead level in drinking water. Available from: http://www.chp. gov.hk/files/pdf/care_plan_for_raised_bll.pdf. Accessed 1 Aug 2017.

42. Dapul H, Laraque D. Lead poisoning in children. Adv Pediatr 2014;61:313-33.

43. Woolf AD, Goldman R, Bellinger DC. Update on the clinical management of childhood lead poisoning. Pediatr Clin North Am 2007;54:271-94, viii.

44. Advisory Committee on Childhood Lead Poisoning Prevention (ACCLPP). Recommendations for blood lead screening of young children enrolled in medicaid: targeting a group at high risk. MMWR Recomm Rep 2000;49(RR14):1-13.

45. Binns HJ, Campbell C, Brown MJ; Centers for Disease Control and Prevention Advisory Committee on Childhood Lead Poisoning Prevention. Interpreting and managing blood lead levels of less than $10 \mathrm{microg} / \mathrm{dL}$ in children and reducing childhood exposure to lead: recommendations of the Centers for Disease Control and Prevention Advisory Committee on Childhood Lead Poisoning Prevention. Pediatrics 2007;120:e1285-98.

46. Centers for Disease Control and Prevention (CDC) Advisory Committee on Childhood Lead Poisoning Prevention. Interpreting and managing blood lead levels $<10 \mathrm{microg} / \mathrm{dL}$ in children and reducing childhood exposures to lead: recommendations of CDC's Advisory Committee on Childhood Lead Poisoning Prevention. MMWR Recomm Rep 2007;56(RR-8):1-16.

47. Lowry JA. Childhood lead poisoning: management. Available from: https://www.uptodate.com/contents/ childhood-lead-poisoning-management. Accessed 2 Jan 2017.

48. Kathuria P. Lead toxicity. Prognosis. Available from: http:// emedicine.medscape.com/article/1174752-overview\#a6. Accessed 1 Aug 2017.

49. Lanphear BP, Dietrich K, Auinger P, Cox C. Cognitive deficits associated with blood lead concentrations $<10$ microg/dL in US children and adolescents. Public Health Rep 2000;115:521-9.

50. Canfield RL, Henderson CR Jr, Cory-Slechta DA, Cox C, Jusko TA, Lanphear BP. Intellectual impairment in children with blood lead concentrations below 10 microg per deciliter. N Engl J Med 2003;348:1517-26.

51. Jusko TA, Henderson CR, Lanphear BP, Cory-Slechta DA, Parsons PJ, Canfield RL. Blood lead concentrations $<10$ microg/dL and child intelligence at 6 years of age. Environ Health Perspect 2008;116:243-8.

52. Chiodo LM, Jacobson SW, Jacobson JL. Neurodevelopmental effects of postnatal lead exposure at very low levels. Neurotoxicol Teratol 2004;26:359-71.

53. Amato MS, Moore CF, Magzamen S, et al. Lead exposure and educational proficiency: moderate lead exposure and educational proficiency on end-of-grade examinations. Ann Epidemiol 2012;22:738-43.

54. Zhang N, Baker HW, Tufts M, Raymond RE, Salihu H, Elliott MR. Early childhood lead exposure and academic achievement: evidence from Detroit public schools, 20082010. Am J Public Health 2013;103:e72-7. 